\title{
The Clinical Effectiveness of School Screening Programme for Idiopathic Scoliosis in Malaysia
}

\author{
*Deepak AS, MS Orth, Ong JY, MBBS, Choon DSK, FRCS, Lee CK, MS Orth, Chiu CK, MS Orth, \\ Chan CYW, MS Orth, Kwan MK, MS Orth
}

National Orthopaedic Center of Excellence for Research and Learning (NOCERAL), University of Malaya, Kuala Lumpur, Malaysia

*Department of Orthopaedic Surgery, Prince Court Medical Center, Kuala Lumpur, Malaysia

\begin{abstract}
(c) (1)
This is an open-access article distributed under the terms of the Creative Commons Attribution License, which permits unrestricted use, distribution, and reproduction in any medium, provided the original work is properly cited
\end{abstract}

Date of submission: 30th November 2016

Date of acceptance: 13th February 2017

\begin{abstract}
Introduction: There is no large population size study on school screening for scoliosis in Malaysia. This study is aimed to determine the prevalence rate and positive predictive value (PPV) of screening programme for adolescent idiopathic scoliosis.

Materials and Methods: A total of 8966 voluntary school students aged 13-15 years old were recruited for scoliosis screening. Screening was done by measuring the angle of trunk rotation (ATR) on forward bending test (FBT) using a scoliometer. ATR of 5 degrees or more was considered positive. Positively screened students had standard radiographs done for measurement of the Cobb angle. Cobb angle of $>10^{\circ}$ was used to diagnose scoliosis. The percentage of radiological assessment referral, prevalence rate and PPV of scoliosis were then calculated.

Results: Percentage of radiological assessment referral $\left(\right.$ ATR $\left.>5^{\circ}\right)$ was $4.2 \%(182 / 4381)$ for male and $5.0 \%$ (228/4585) for female. Only $38.0 \%$ of those with ATR $>5^{\circ}$ presented for further radiological assessment. The adjusted prevalence rate was $2.55 \%$ for Cobb angle $>10^{\circ}, 0.59 \%$ for $>20^{\circ}$ and $0.12 \%$ for $>40^{\circ}$. The PPV is $55.8 \%$ for Cobb angle $>10^{\circ}, 12.8 \%$ for $>20^{\circ}$ and $2.6 \%$ for $>40^{\circ}$.

Conclusions: This is the largest study of school scoliosis screening in Malaysia. The prevalence rate of scoliosis was $2.55 \%$. The positive predictive value was $55.8 \%$, which is adequate to suggest that the school scoliosis screening programme did play a role in early detection of scoliosis. However, a cost effectiveness analysis will be needed to firmly determine its efficacy.
\end{abstract}

Key Words: adolescent idiopathic scoliosis, school screening, prevalence, positive predictive value

\section{INTRODUCTION}

Scoliosis is a three-dimensional deformity of the spine defined as a lateral curvature of the spine in the coronal plane with a Cobb angle more than 10 degrees. Idiopathic scoliosis had the prevalence of about $0.4 \%$ to $7 \%$ amongst adolescents in Asian countries ${ }^{1-12}$. In patients with idiopathic scoliosis, earlier detection and diagnosis allows early conservative treatment, which is bracing and this can avoid unnecessary surgery and preserve a higher health-related quality of life scores ${ }^{13,14}$. Late detection may lead to higher rates of patient needing surgery and if this condition is left untreated, it can progress to severe scoliosis, which has been shown to affect pulmonary function of patients ${ }^{14,15}$. Moreover, the severe scoliotic deformity will also affect patients' self-image and this may leave an irreversible psychological impact on this group of patients.

A school screening programme can detect students with early deformity. The percentage of students diagnosed of scoliosis amongst those positively screened is known as the positive predictive value (PPV). Amongst the Asian countries, the PPV of school scoliosis screening ranged from $20 \%$ to $70 \%{ }^{1}$, $3,4,6,9-11$. A previous study done in Malaysia has reported a PPV school scoliosis screening of $35.7 \%$ with a small study population of 832 students $^{6}$. Therefore, we aimed to report the prevalence rate and the PPV based on a larger series of school screening for adolescent scoliosis in Malaysia.

\section{MATERIALS AND METHODS}

This was a cross sectional screening programme carried out in schools (11 schools) which agreed to participate in Kuala Langat, Selangor, Malaysia from August 1996 to April 1999. This region had a population of a mixture of rural and urban people. Based on previous prevalence studies ${ }^{16,17}$, we have recruited students aged between 13 and 15 years old from 11 secondary schools. A total of 8966 students (4381 males and 4585 females) were recruited. 
Table I: Referral rate for radiographs using a scoliometer screening

\begin{tabular}{|lccccccccc|}
\hline Age & \multicolumn{2}{c}{$\mathbf{1 3}$} & $\mathbf{2}$ & $\mathbf{1 4}$ & $\mathbf{1 5}$ & \multicolumn{2}{c|}{$\mathbf{1 3 - 1 5}$} & Total \\
Gender & $\mathbf{M}$ & $\mathbf{F}$ & $\mathbf{M}$ & $\mathbf{F}$ & $\mathbf{M}$ & $\mathbf{F}$ & $\mathbf{M}$ & $\mathbf{F}$ \\
\hline Population screened & 1636 & 1644 & 1469 & 1477 & 1276 & 1464 & 4381 & 4585 & 8966 \\
Positive subjects & 57 & 82 & 59 & 73 & 66 & 73 & 182 & 228 & 410 \\
Referral rate (\%) & 3.5 & 5.0 & 4.0 & 4.9 & 5.2 & 5.0 & 4.2 & 5.0 & 4.6 \\
\hline
\end{tabular}

$\mathrm{M}=$ Male, $\mathrm{F}=$ Female

Table II: Prevalence rate and positive predictive value

\begin{tabular}{|llcccc|}
\hline Cobb angle & \multicolumn{1}{c}{ Prevalence } & $\begin{array}{c}{ }^{*} \text { Adjusted } \\
\text { prevalence rate (\%) }\end{array}$ & Rate (\%) & PPV \\
& \multicolumn{1}{c}{ Rate (\%) } & 95\% Cl & Cl \\
\hline$>10^{\circ}$ & $87 / 8966(0.97)$ & $0.0079,0.0120$ & 2.55 & $87 / 156(55.8)$ & $0.635,0.477$ \\
$>20^{\circ}$ & $20 / 8966(0.22)$ & $0.0014,0.0034$ & 0.59 & $20 / 156(12.8)$ & $0.154,0.101$ \\
$>40^{\circ}$ & $4 / 8966(0.04)$ & $0.0002,0.0011$ & 0.12 & $4 / 156(2.6)$ & $0.0382,0.0129$ \\
\hline
\end{tabular}

PPV = Positive predictive value

*Adjusted prevalence rate $=$ prevalence rate/turn-up rate $\times 100 \%$; turn-up rate $=38 \%$

Table III: Literature reviews of school scoliosis screening in Asian countries

\begin{tabular}{|c|c|c|c|c|c|c|c|c|}
\hline $\begin{array}{l}\text { Year } \\
\text { Published }\end{array}$ & Country & Programme & $\begin{array}{c}\text { Cobb } \\
\text { angle } \\
\text { (degrees) }\end{array}$ & $\begin{array}{l}\text { Sample } \\
\text { size }\end{array}$ & $\begin{array}{c}\text { Age } \\
\text { (years) }\end{array}$ & Gender & PR (\%) & PPV (\%) \\
\hline \multirow[t]{8}{*}{2005} & Singapore & Wong et $a l^{1}$ & $>10$ & 72,699 & $6-7$ & Male & 0.02 & 17.6 \\
\hline & & & & & & Female & 0.05 & 23.7 \\
\hline & & & & & $9-10$ & Male & 0.15 & 24.5 \\
\hline & & & & & & Female & 0.24 & 24.1 \\
\hline & & & & & $11-12$ & Male & 0.21 & 23.8 \\
\hline & & & & & & Female & 1.37 & 50.1 \\
\hline & & & & & $13-14$ & Male & 0.66 & 27.5 \\
\hline & & & & & & Female & 2.22 & 47.7 \\
\hline \multirow[t]{5}{*}{2009} & Singapore & Yong et $a l^{2}$ & $>10$ & 93626 & 9 & Female & 0.27 & - \\
\hline & & & & & 10 & & 0.64 & \\
\hline & & & & & 11 & & 1.58 & \\
\hline & & & & & 12 & & 2.22 & \\
\hline & & & & & 13 & & 2.49 & \\
\hline \multirow[t]{3}{*}{2010} & Hong Kong & Luk et $a l^{3}$ & $>10$ & 157,444 & $10-19$ & - & 2.49 & 76.5 \\
\hline & & & $>20$ & & & & 1.39 & 36.5 \\
\hline & & & $>40$ & & & & 0.23 & 8.1 \\
\hline \multirow[t]{2}{*}{2011} & Korea & Suh et $a l^{4}$ & $>10$ & $1,134,890$ & $10-14$ & Male & 1.97 & 41.0 \\
\hline & & & & & & Female & 4.65 & 51.0 \\
\hline \multirow[t]{4}{*}{2011} & Japan & Ueno et $a l^{5}$ & $>10$ & 255,875 & $11-12$ & Male & 0.04 & - \\
\hline & & & & & & Female & 0.78 & \\
\hline & & & & & 13 & Male & 0.25 & \\
\hline & & & & & & Female & 2.51 & \\
\hline 2013 & Malaysia & Htwe et $a I^{6}$ & $>10$ & 832 & 12 & - & 0.6 & 35.7 \\
\hline \multirow[t]{2}{*}{2014} & Korea & Lee et $a l^{7}$ & $>10$ & 37,856 & 11 & Male & 0.05 & - \\
\hline & & & & & & Female & 0.35 & \\
\hline \multirow[t]{2}{*}{2015} & Hong Kong & Fong et $a l^{8}$ & $>10$ & 306,144 & 5th G - 19 & Male & 2.2 & 81.0 \\
\hline & & & & & & Female & 4.8 & \\
\hline \multirow[t]{6}{*}{2015} & Japan & Yamamoto et al ${ }^{9}$ & $>10$ & 195,149 & 5 th G & Male & 0.06 & 33.3 \\
\hline & & & & & & Female & 0.34 & \\
\hline & & & & & 6th G & Male & 0.01 & \\
\hline & & & & & & Female & 0.37 & \\
\hline & & & & & 7th G & Male & 0.06 & \\
\hline & & & & & & Female & 0.73 & \\
\hline \multirow[t]{2}{*}{2016} & China & Du et $a /^{10}$ & $>10$ & 6,824 & $6-17$ & Male & 1.96 & 33.8 \\
\hline & & & & & & Female & 3.11 & 43.2 \\
\hline 2016 & China & Hengwei et al ${ }^{11}$ & $>10$ & 99,695 & $10-19$ & - & 5.14 & - \\
\hline \multirow[t]{4}{*}{2016} & China & Zheng et al ${ }^{12}$ & $>10$ & 11,024 & $10-11$ & Male & 0.17 & - \\
\hline & & & & & & Female & 0.08 & \\
\hline & & & & & $12-13$ & Male & 0.52 & \\
\hline & & & & & & Female & 0.88 & \\
\hline \multirow[t]{3}{*}{-} & Malaysia & Present Study & $>10$ & 8,966 & $13-15$ & - & 2.55 & 55.8 \\
\hline & & & $>20$ & & & & 0.59 & 12.8 \\
\hline & & & $>40$ & & & & 0.12 & 2.6 \\
\hline
\end{tabular}

$P R=$ Prevalence rate, $P P V=$ Positive predictive value,$G=$ Grade 


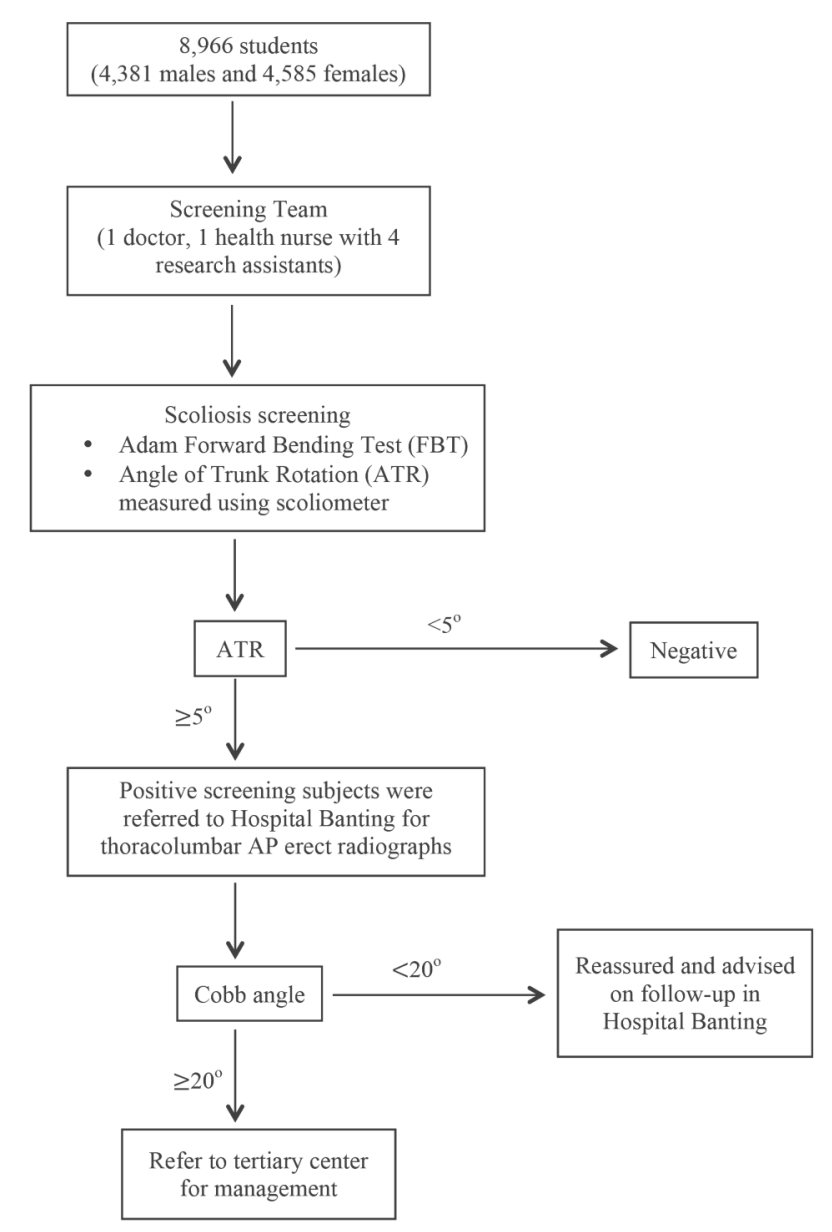

Fig. 1: Screening protocol of Adolescent Idiopathic Scoliosis in Kuala Langat, Malaysia.

The school screening team consisted of a doctor, a health nurse and four research assistants. All the volunteered students were examined with Adam forward bending test at first. The angle of trunk rotation (ATR) was then measured at thoracic, thoracolumbar and lumbar region by using a scoliometer if the Adam forward bending test detected any asymmetry of the trunk. ATR of 5 degrees or more was considered positive. These positive screened students were referred to the nearest district hospital, Hospital Banting for anteroposterior standing whole-spine radiograph. Cobb angle would be measured. Those with Cobb angle of 20 degrees or more would be referred to the scoliosis clinic at the tertiary centre, University Malaya Medical Center for further assessment and management. The rest of the subjects were reassured and advised on follow-up (Fig. 1).

For radiological assessment, we used Cobb angle of $>10$ degrees as suggested by Scoliosis Research Society to diagnose scoliosis. Based on the Cobb angle measured from the radiographs, the prevalence rate was calculated. The positive predictive value (PPV), which is the percentage of students diagnosed of scoliosis amongst those positively screened, which denotes a measure of clinical effectiveness, was also calculated. The prevalence rate and PPV analysis were further divided into three categories according to the Cobb angle i.e. $>10$ degrees, $>20$ degrees and $>40$ degrees).

\section{RESULTS}

In this screening programme, 8966 students were screened using scoliometer. There were 410 students screened positive i.e. ATR $>5$ degrees in this programme but only $156(38.0 \%)$ students turned up for the radiological assessment. Those who failed to attend the radiological examination were not included in the statistical analysis.

There was a higher referral rate of female students compared to male students (Table I). The overall referral rate of male students was $4.2 \%$ compared to $5.0 \%$ for female students. The referral rate for male students rose from $3.5 \%$ for 13 year-old students, $4.0 \%$ for 14 -year-old students to $5.2 \%$ for 15 -year-old students. The female students recorded almost similar referral rate for 13-year-old (5.0\%), 14-year-old (4.9\%) and 15-year-old (5.0\%).

The prevalence rate is $0.97 \%$ for Cobb angle more than 10 degrees, $0.22 \%$ for more than 20 degrees and $0.04 \%$ for more than 40 degrees. Taking the drop-out rate of $62 \%$ into consideration, the adjusted prevalence rate is $2.55 \%$ for Cobb angle more than 10 degrees, $0.59 \%$ for more than 20 degrees and $0.12 \%$ for more than 40 degrees. The adjusted prevalence rate is $2.55 \%, 0.59 \%$ and $0.12 \%$ for Cobb angle $>10^{\circ},>20^{\circ}$ and $>40^{\circ}$ respectively (Table II).

Based on the 156 positive screened students who turned up, the positive predictive value (the percentage of students diagnosed of scoliosis amongst those positively screened using scoliometer) was $55.8 \%$ for Cobb angle more than 10 degrees, $12.8 \%$ for more than 20 degrees and $2.6 \%$ for more than 40 degrees (Table II).

\section{DISCUSSION}

Screening is defined as 'the presumptive identification of unrecognised disease or defect by application of tests, examination or procedures which can be applied rapidly' ${ }^{18}$. In adopting this definition, the commission on chronic illness further stated that 'screening tests sort out apparently well persons who have a disease from those who probably do not'. A screening test is not intended to be diagnostic. Persons with positive or suspicious findings must refer to their physicians for further diagnosis and treatment. Scoliosis screening fits into this definition because it is able to detect those with true scoliosis from those without and refer them for subsequent diagnostic test to facilitate early intervention, thus decreasing need for surgery through bracing. 
The first scoliosis screening programme was started in Delaware, USA in the late 1950s and subsequently scoliosis screenings were carried out elsewhere, either by legislation or voluntarily ${ }^{1,16,19-23}$. The implementation of school scoliosis screening was debatable over decades as there were large variations across studies in term of its PPV. The variations were likely due to the diversity in study design, referral criteria, screening tests used, frequency of screening and duration of follow-up ${ }^{24}$. However, Ohrt-Nissen et al ${ }^{25}$ confirmed in their study that referred patients by general practitioner from schools without screening programme had a larger curve magnitude compared to patient from schools with a scoliosis screening programme.

The impact of scoliosis screening on the reduction of surgical treatment was described in several studies. Lonstein et $a l^{26}$ had screen a quarter of a million children for eight years and 3.4\% were referred for evaluation and $1.2 \%$ were found to have scoliosis. Since the initiation of the school screening, the number of children requiring surgical procedure diminished and the average curve for those who had surgery reduced from 60 degrees to 42 degrees. Montgomery and Willner ${ }^{27}$ had found that the demand for surgery reduced from $45 \%$ to $10 \%$ in the screening group of patients and concluded that bracing outcome was better in the screening group because of the earlier onset of intervention. Bunge et $a l^{28}$ found that there was no evidence that screening for scoliosis reduced the need for surgery. This may be due to the controversies they had in the effectiveness of early treatment with bracing and students screened positive might not had brace treatment initiated immediately.

In 2013, the BrAIST clinical trial confirmed the effectiveness of bracing in AIS. This was a multicenter prospective study with enrollment of 242 patients. 116 patients were randomized to either bracing or observation whereas 126 chose between bracing or observation. When both randomized and preference cohorts were analyzed the treatment success was $72 \%$ after bracing compared to $48 \%$ after observation. In the intention to treat analysis, the rate of treatment success was $75 \%$ among patients randomly assigned to bracing compared to $42 \%$ among those randomly assigned to observation. The trial was terminated earlier due to the clear advantage of bracing in arresting progression in AIS $^{29}$.

When it comes to national screening programme, cost effectiveness analysis plays an important factor to drive its implementation. Lonstein et $a l^{26}$ found that the cost of a school screening programme for scoliosis was low and it was a cost effective measure which should be carried out. Montgomery et $a l^{30}$ further added that clinical screening using scoliometer that was combined with Moire screening would further improve the cost effectiveness of the programme. Soucacos et $a^{31}$ found that the cost of screening process was negligible compared to the benefit of decreased number of operative procedures performed after the screening programme, the identification of a large number of previously undiagnosed curves which were subsequently treated with operation or brace, and the identification of children who were at high risk of progression. Thilagaratnam et $a l^{32}$ found that school based scoliosis screening programme was cost effective and the effectiveness can be improved further by targeting the screening at high risk groups, such as prepubertal females. However, Morais et a $l^{16}$ found that the screening cost per child was high in Canada and mass screening for idiopathic scoliosis was not justified. This was supported by Yawn et $a l^{33}$ who found the school scoliosis screening was significantly more costly than previously reported.

The measurement of ATR using scoliometer was a noninvasive, radiation free and comparatively cheap method of screening. It can be easily implemented and it had been proven to have good correlation with radiological analysis $(\mathrm{r}=0.7, \mathrm{p}<0.05)$ and very good intra-rater reliability ${ }^{34,35}$. By using this screening method, we found that percentage of students referred for radiographs in the present study was $4.6 \%$. Therefore, 1 in 20 students will be referred for further radiography. There were more females referred with the male to female ratio of $1: 1.2$. The prevalence rate of idiopathic scoliosis for this study, according to the definition of scoliosis with the Cobb angle $>10$ degrees, was $2.55 \%$. This corresponds to the prevalence of idiopathic scoliosis in Asian countries that varies between $0.4 \%-7 \%{ }^{1-12}$ (Table III).

The PPV (the percentage of students diagnosed of scoliosis amongst those positively screened) for this study was $55.8 \%$ for students with a Cobb angle of more than 10 degrees. This finding was higher than previously reported PPV for scoliosis screening in Malaysia by Htwe et $a l^{6}$. We also found that our school screening programme was more predictive than other Asian country such as Singapore $(27.5 \%-47.7 \%)^{1}$, Korea $(41.0 \%-51.0 \%)^{4}$, China $(33.8 \%$ $43.2 \%)^{10}$, and Japan $(33.3 \%)^{9}$. Only the school screening programme done in Hong Kong ${ }^{3,8}$ had a higher PPV than our study $(76.5 \%-81.0 \%)$. In their study, those negatively screened who had ATR between 0 - 2 had the tests repeated biennially, those negatively screened who had with ATR 3 4 had the test repeated annually. And those with ATR between 5 and 14 or obvious signs of trunk or shoulder asymmetry were further evaluated by Moirè topography. These additional interventions were possibly the cause of the improvement in PPV in their school screening programme. Thus, with a PPV of $55.8 \%$, we found that school programme can be a viable intervention to improve the detection and to employ early treatment of scoliosis in Malaysia.

A major limitation of this study was the dropout rate. There were 410 students screened positive in this programme but only $156(38.0 \%)$ students turned up for the radiological 
assessment. This was a voluntary programme and the requirement for a radiographic evaluation was not compulsory. Furthermore, parents' health awareness regarding scoliosis was low. This may explain the high dropout rate in this study. The method of sampling in this study may consist selection bias and hence not reflective the true prevalence and positive predictive value for Malaysia.

\section{CONCLUSION}

The prevalence rate of scoliosis was $2.55 \%$ and scoliosis was more common amongst female. The positive predictive value, which reflects the percentage of students diagnosed of scoliosis amongst those positively screened using scoliometer, was $55.8 \%$. This predictive value was adequate to suggest that the school screening programme did play a role in early detection of scoliosis. However, a cost effectiveness analysis will be needed in order to firmly determine its efficacy.

\section{REFERENCES}

1. Wong HK, Hui JH, Rajan U, Chia HP. Idiopathic scoliosis in Singapore schoolchildren: a prevalence study 15 years into the screening program. Spine. 2005; 30(10): 1188-96.

2. Yong F, Wong HK, Chow KY. Prevalence of adolescent idiopathic scoliosis among female school children in Singapore. Ann Acad Med Singapore. 2009; 38(12): 1056-63.

3. Luk KD, Lee CF, Cheung KM, Cheng JC, Ng BK, Lam TP, et al. Clinical effectiveness of school screening for adolescent idiopathic scoliosis: a large population-based retrospective cohort study. Spine. 2010; 35(17): 1607-14.

4. Suh SW, Modi HN, Yang JH, Hong JY. Idiopathic scoliosis in Korean schoolchildren: a prospective screening study of over 1 million children. Eur Spine J. 2011; 20(7): 1087-94.

5. Ueno M, Takaso M, Nakazawa T, Imura T, Saito W, Shintani R, et al. A 5-year epidemiological study on the prevalence rate of idiopathic scoliosis in Tokyo: school screening of more than 250,000 children. J Orthop Sci. 2011; 16(1): 1-6.

6. Htwe K, Abdullah AT, Amat A, Jalaluddin A, Aung MMT, Zaw MS. Prevalence of Scoliosis in Standard 6 Female Primary School Students in Marang District, Terengganu. Int J Med Sci. 2013; 46(3): 1299.

7. Lee JY, Moon SH, Kim HJ, Park MS, Suh BK, Nam JH, et al. The prevalence of idiopathic scoliosis in eleven year-old Korean adolescents: a 3 year epidemiological study. Yonsei Med J. 2014; 55(3): 773-8.

8. Fong DY, Cheung KM, Wong YW, Wan YY, Lee CF, Lam TP, et al. A population-based cohort study of 394,401 children followed for 10 years exhibits sustained effectiveness of scoliosis screening. Spine J. 2015; 15(5): 825-33.

9. Yamamoto S, Shigematsu H, Kadono F, Tanaka Y, Tatematsu M, Okuda A, et al. Adolescent Scoliosis Screening in Nara City Schools: A 23-Year Retrospective Cross-Sectional Study. Asian Spine J. 2015; 9(3): 407-15.

10. Du Q, Zhou X, Negrini S, Chen N, Yang X, Liang J, et al. Scoliosis epidemiology is not similar all over the world: a study from a scoliosis school screening on Chongming Island (China). BMC Musculoskelet Disord. 2016;17:303.

11. Hengwei F, Zifang H, Qifei W, Weiqing T, Nali D, Ping Y, et al. Prevalence of Idiopathic Scoliosis in Chinese Schoolchildren: A Large, Population-Based Study. Spine. 2016; 41(3): 259-64.

12. Zheng Y, Wu X, Dang Y, Yang Y, Reinhardt JD, Dang Y. Prevalence and determinants of idiopathic scoliosis in primary school children in Beitang district, Wuxi, China. J Rehabil Med. 2016; 48(6): 547-53.

13. Lee H, Choi J, Hwang JH, Park JH. Health-related quality of life of adolescents conservatively treated for idiopathic scoliosis in Korea: a cross-sectional study. Scoliosis Spinal Disord. 2016; 11: 11

14. Torell G, Nordwall A, Nachemson A. The changing pattern of scoliosis treatment due to effective screening. J Bone Joint Surg Am. 1981; 63(3): 337-41.

15. Weinstein SL, Zavala DC, Ponseti IV. Idiopathic scoliosis: long-term follow-up and prognosis in untreated patients. J Bone Joint Surg Am. 1981; 63(5): 702-12.

16. Morais T, Bernier M, Turcotte F. Age and sex-specific prevalence of scoliosis and the value of school screening programs. $A m J$ Public Health. 1985; 75(12): 1377-80. 
17. Konieczny MR, Senyurt H, Krauspe R. Epidemiology of adolescent idiopathic scoliosis. J Child Orthop. 2013; 7(1): 3-9.

18. Whitby LG. Screening for disease: Definitions and criteria. Lancet (London, England). 1974; 2(7884): 819-22.

19. Gore DR, Passehl R, Sepic S, Dalton A. Scoliosis screening: results of a community project. Pediatrics. 1981; 67(2): 196-200.

20. Hansen TB. [Adolescent idiopathic scoliosis among girls in the Herning region. A follow-up of girls with adolescent idiopathic scoliosis found in an earlier screening at school]. Ugeskr Laeger. 1994; 156(35): 4979-82.

21. Ohtsuka Y, Yamagata M, Arai S, Kitahara H, Minami S. School screening for scoliosis by the Chiba University Medical School screening program. Results of 1.24 million students over an 8-year period. Spine. 1988; 13(11): 1251-7.

22. Pruijs JE, van der Meer R, Hageman MA, Keessen W, van Wieringen JC. The benefits of school screening for scoliosis in the central part of The Netherlands. Eur Spine J. 1996; 5(6): 374-9.

23. Karachalios T, Roidis N, Papagelopoulos PJ, Karachalios GG. The efficacy of school screening for scoliosis. Orthopedics. 2000; 23(4): 386-91; quiz 92-3.

24. Fong DY, Lee CF, Cheung KM, Cheng JC, Ng BK, Lam TP, et al. A meta-analysis of the clinical effectiveness of school scoliosis screening. Spine. 2010; 35(10): 1061-71.

25. Ohrt-Nissen S, Hallager DW, Henriksen JL, Gehrchen M, Dahl B. Curve Magnitude in Patients Referred for Evaluation of Adolescent Idiopathic Scoliosis: Five Years' Experience From a System Without School Screening. Spine Deform. 2016; 4(2): $120-4$.

26. Lonstein JE, Bjorklund S, Wanninger MH, Nelson RP. Voluntary school screening for scoliosis in Minnesota. J Bone Joint Surg Am. 1982; 64(4): 481-8.

27. Montgomery F, Willner S. Screening for idiopathic scoliosis. Comparison of 90 cases shows less surgery by early diagnosis. Acta Orthop Scand. 1993; 64(4): 456-8.

28. Bunge EM, Juttmann RE, van Biezen FC, Creemers H, Hazebroek-Kampschreur AA, Luttmer BC, et al. Estimating the effectiveness of screening for scoliosis: a case-control study. Pediatrics. 2008; 121(1): 9-14.

29. Weinstein SL, Dolan LA, Wright JG, Dobbs MB. Effects of bracing in adolescents with idiopathic scoliosis. N Engl J Med. 2013; 369(16): 1512-21.

30. Montgomery F, Persson U, Benoni G, Willner S, Lindgren B. Screening for scoliosis. A cost-effectiveness analysis. Spine. 1990; 15(2): 67-70.

31. Soucacos PN, Soucacos PK, Zacharis KC, Beris AE, Xenakis TA. School-screening for scoliosis. A prospective epidemiological study in northwestern and central Greece. J Bone Joint Surg Am. 1997; 79(10): 1498-503.

32. Thilagaratnam S. School-based screening for scoliosis: is it cost-effective? Singapore Med J. 2007; 48(11): 1012-7.

33. Yawn BP, Yawn RA. The estimated cost of school scoliosis screening. Spine. 2000; 25(18): 2387-91.

34. Bonagamba GH, Coelho DM, Oliveira AS. Inter and intra-rater reliability of the scoliometer. Rev Bras Fisioter. 2010; 14(5): $432-8$.

35. Coelho DM, Bonagamba GH, Oliveira AS. Scoliometer measurements of patients with idiopathic scoliosis. Braz J Phys Ther. 2013; 17(2): 179-84. 